\title{
Stakeholder attitudes towards employability in a Sino-British university
}

\author{
Sarah Speight ${ }^{1}$, Natasa Lackovic ${ }^{1}$, Lucy Cooker $^{1}$ \\ Sarah.speight@nottingham.ac.uk \\ ${ }^{1}$ School of Education, The University of Nottingham, United Kingdom
}

\begin{abstract}
In 2004 the University of Nottingham opened its branch campus, the University of Nottingham Ningbo China (UNNC). Degree-awarding powers for UNNC remain with the UK, but there is recognition that Nottingham must understand the specific context of its Chinese branch; provision therefore operates according to the principal of equivalence rather than of replication. This paper explores stakeholder attitudes towards the University's Nottingham Advantage Award. This is an extra-curricular programme designed to support students in the development of their 'employability'. Launched in the UK in 2008, it was piloted at UNNC in 2010-11 and has now completed its first full year of operation. Twenty-three interviews were conducted with staff and students at UNNC. These were analysed alongside interviews carried out in the UK and with reference to the research literature. This provided an understanding of the role of the Award overall and in the UNNC context. The study shows that while stakeholders hold broadly similar views in the UK and China, there are subtle differences of emphasis concerning the understanding of, and responsibility for, learning for employability. In addition, a group of China-specific themes emerged from the UNNC interviews that indicated recognition of the need to differentiate priorities and provision for each site. The paper concludes that the challenge for the Award at UNNC is to serve both global and local agendas and that it should strive to reduce the 'information asymmetry' existing between stakeholders to promote effective graduate employability.
\end{abstract}

Keywords: employability, Sino-British, stakeholder attitudes, human capital, curriculum

\section{Introduction}

Employability is a well-established field of academic research with countless studies demonstrating the shifting discourse from human capital to human development, from skills to attributes or capabilities, and from individual career development to global citizenship and contribution to a just society. The role of universities in education for employability is a current, if contested topic, with academics taking opposing positions either in 'defence' of the independence of disciplinary knowledge and understanding, or in support of the interconnectedness of subject and employability learning (Barrie, 2009; Yorke, 2010). In western higher education, there has been a move away from "attribute development in specialist modules or extracurricular activity to a more holistic approach that embeds employability as part of academic learning" (Harvey, 2005, p.16).

Behind the academic debate lie real issues of politics, policy, philosophical and economic context and social equity that impact upon the strategic direction of education for employability. There is no single solution to the challenge of equipping today's graduates for productive and worthwhile futures. Strategies for employability are required on local, national and global levels. In 2011 an estimated 10 million higher education graduates were seeking employment in China (Shi \& Sewell, 2012). China's move from elite to mass higher 
education with the introduction of student-fees and the removal of the job assignment system means that graduate unemployment is now a real prospect. Economic growth has not produced sufficient graduate-entry positions and it has been suggested that there may be up to 30\% graduate unemployment (Li \& Morgan, 2008; Ennew \& Fujia, 2009; Bai, 2010; Shi \& Sewell, 2012). The social consequences of this are serious, including the negative impact of parents being unable to benefit from investment in their children's education, and of children being unable to pay back parental debt (Bai, 2010).

China's expansion of higher education fits into a specific cultural and historic context that has been acknowledged and explored by authors including Bai $(1998 ; 2006 ; 2010)$. Human capital theory has provided the dominant rationale for investment in education since the late 1970s and the end of the Cultural Revolution (Bai, 2010). This links education directly to economic growth, seeing education as increasing the productivity and capability of the individual who can thereby make a more effective contribution to the productivity of the nation. In human capital theory, education is an investment in the future as expressed in Bai's (2010) China-specific formula of schooling $\rightarrow$ examination $\rightarrow$ higher degree $=$ good job + good income + higher social status. In 1993 China introduced student fees to higher education and gave students the opportunity to choose their career paths by removing the system of job assignment (Bai, 2010). For Bai, this has led to increased instrumentalism in students as their focus shifts towards their individual prospects and away from the needs of the state. One of the dangers of human capital theory is that it can render education an instrumental force by its economic focus and discourse of production. However, softer articulations exist which incorporate the role of education in social and political developments, for example in forging democratic societies or developing creative solutions (Olaniyan \& Okemakinde, 2008). Alternative frameworks posit human capital alongside social and identity capital in proposing a model for effective learning (Schuller \& Watson, 2009).

To realise the full benefits of an expanded higher education sector, China needs to find a softer articulation that suits its context. Social prestige and good jobs can also equate with contribution to a broader good and to the welfare of society (Wu \& Morgan, 2011). One solution is to find the common ground between traditional values and modern requirements (Bai, 1998, 2010). By reviving the older traditions of Neo-Confucianism or "education for fostering one's humanity" (Bai, 2010, p.104), humane talent can be developed in equal measure to human capital. As Jiao Shuqing, Deputy Director of the Department of Student Affairs, State Education Commission, said in a speech in 1993: higher education needs to educate students "on how to combine their own interest with the state interests" (Bai, 1998, p.531). Yet, caution is advised if accepting that Chinese graduates are more selfish than they were in the past as a result of economic and political reform. The rise of money power (Bai, 1998) may have led to a concentration on graduate outcomes for the individual but a significant aspect of this will be the recognition of the sacrifice that parents have made to send their children to university. Higher earnings also give the opportunity to pay back and are about a whole set of family-focused values that may be less obvious in the west (although perhaps this will be a new phenomenon in the UK from 2015 when the first graduates emerge with debts resulting from the introduction of variable fees in 2012).

Internationally, employability initiatives within higher education focus upon equipping the individual for a productive future, both socially and economically. However, these initiatives can overlook a range of factors beyond the control of the student and also sometimes of the university. Institutional reputation is a major screening mechanism that will impact upon job prospects. Furthermore, the signal effects of degree subject, classification, English language competency, significant extra-curricular experience in leadership, will all play their part alongside issues of gender, family history and residential origin ( $\mathrm{Li}$, Ding \& Morgan, 2008; 2009). 
The graduate comes with their individual social or cultural capital but, in addition, faces the challenge of ensuring that the choices they make on entry to and during their higher education equip them for that worthwhile future on whatever level they choose to conceive of it (financial, social, well-being). There is evidence that educational growth will not necessarily resolve China's skills shortage. A study of employer perceptions drawn from private and multinational companies based in Shanghai, Beijing, Xi'an, Ningbo, Zhuhai and Chongqing suggested that there was still a mismatch between what employers look for in their graduate recruits, and what graduates think employers want (Davies, Xinyan \& Wei, 2012). The researchers found companies struggling to recruit suitable graduates and unhappy at the high costs of training new staff (partly due to the expectation that such investment would lead to talent poaching). Employers wanted graduates with good qualifications (including interpersonal skills), but also with a particular personality and attitude:

"An employer would wish his staff to be honest, loyal, diligent and generally fit well into the organisational culture. If there is no good fit into the culture, the employee will not be motivated and will either cause problems and will probably resign after a period of time........Staff need to be passionate in their work, be serious and dedicated and pay attention to details" (Davies et al., 2012, p.7).

Of particular note are the requirements for organisational fit and passion. Shi and Sewell's (2010) study of the entrepreneurial spirit explored the different perspectives of stakeholders at the University of Central Lancashire (UCLan) in the UK and the Shanghai Institute of Foreign Trade (SIFT) in China. While the attitudes of students at UCLan and SIFT were broadly similar, there were differences in the characteristics of each student group. At SIFT, there was both a higher proportion of proactive students who were highly motivated and knew what they wanted, but also a higher proportion of 'drifters' who had no great expectations of either their education or their career. UCLan's students were less entrepreneurial but more likely to be methodically preparing themselves for employment by the acquisition of skills and information. These differences were related to cultural expectations, with UK students being defined as customers of higher education and Chinese students as products of the system. The suggested outcome of these approaches was that UCLan students were supported to develop themselves as individuals via flexible and tailored programmes, while SIFT focused upon understanding the needs of employers and seeking to match students to these. Cultural difference may explain the different attitudes of students and the different responses of institutions to education for employability (Shi \& Sewell, 2010).

The Chinese labour market is made complex because of the co-existence of a command and control economy alongside a market economy (Velde, 2009). This means that graduates have to carefully adapt themselves and their applications to the context of the employer they are approaching. To give an extreme example, compliance may be a requirement of one employer, an ability to be creative and to think outside of the box a requirement of another.

Interviews with employers (2008 and 2009), revealed issues related to the command and control economy (Davies, Xinyan \& Wei, 2012). Certain occupations were considered to be low-status. Recruitment to graduate positions within such industries was problematic due to face (for example, the tourism industry and lower managerial positions in general). Positions might be rejected if starting salaries and working conditions were considered to be noncommensurate with student perceptions of graduate worth. In addition, the problems of relocation within China, and possible impact upon access to benefits for non-registered residents, acted as recruitment impediments. These and other studies suggest that overall there is an information asymmetry between employers and graduates and that part of the role of higher education should be to reduce this (Li, Morgan \& Ding, 2008). 


\section{The University of Nottingham Ningbo China}

The University of Nottingham Ningbo China (UNNC) opened in 2004 as a partnership between The University of Nottingham UK (UNUK) and the Zhejiang Wanli Education Group. UNNC currently offers a wide range of degrees grouped within the Faculties of Arts and Humanities, Science and Engineering and Social Sciences. In 2011-12 there were 5,000 registered undergraduate and postgraduate students.

In opening its international campuses in China and also in Malaysia, Nottingham has sought to deliver top quality education in both a global context and a local (China, Malaysia, UK) context, seeking "to educate generations of students as truly international citizens, rooted in their own cultures but aware of, and sympathetic towards, other cultures" (Ennew \& Fujia, 2009 , p.30). The challenge has been to broaden outlooks and deepen capabilities while also respecting the traditions of the host country and ensuring that Nottingham degrees in China are fit for local purpose (equivalence rather than replication). The target students for UNNC are Chinese. In its 2012 return to the Observatory for Borderless Higher Education (OBHE), Nottingham reported that $94 \%$ of UNNC students were from China, with $1 \%$ from the UK and $5 \%$ from the rest of the world; this can be contrasted with the University's operation in Malaysia, where $60 \%$ of the students are from the host nation, $1 \%$ from the UK and $39 \%$ from the rest of the world (OBHE, 2012). As is common with transnational education initiatives in China, most of the courses offered by UNNC are professional or vocational with business and engineering the largest disciplines (Huang, 2007).

The Teaching and Learning Strategy for UNNC includes providing all students with the opportunity to gain credits and formal recognition for extra-curricular activities and experience which enhance employability and to review the curriculum to promote employability, to reflect both the local and international character of the University (UNNC Report to Senate June 2011). UNNC is committed to supporting its graduates to gain worthwhile employment.

Career Development Office surveys, conducted six months after graduation, reveal most UNNC degrees to be returning a $100 \%$ employment record where employment includes further study. For example, nearly $60 \%$ of $2008 / 2009$ graduates with the BA International Communications went on to postgraduate study, often in Europe or America. However, there is a need for more longitudinal data to fully assess the rate of return of investment in higher education, and the differential benefits of under and post-graduate qualifications ( $\mathrm{Li}$, Zhao \& Morgan, 2011). A MyCOS survey conducted by a Chinese education data consultation and assessment company revealed that, within the national context, full-time employment for 2009 graduates six months after graduation had fallen to 49.5\% (Bai, 2010).

The employability literature shows an increasing move away from instrumental definitions of gaining employment and securing graduate-level employment to more nuanced frameworks for personal development of capabilities or attributes as opposed to skills. This fits well with the mission of a global institution such as Nottingham to develop its' students not just as individual leaders but as functional and fulfilled community members able to make valid contributions and ethical choices. The University's mission statement within the 2010-2015 Strategic Plan includes benefiting the communities around our campuses, and improving life for individuals and societies worldwide. Yet there is a tension between this and the need of the institution to position itself within the various metrics of quality, research, sustainability and employability. The league tables are tools, but the means to securing a strong position in them, according to the literature, must be less instrumental for genuine impact. China's current focus upon a human capital discourse in relation to investment in higher education means that UNNC feels these tensions strongly. 


\section{The Nottingham Advantage Award}

In 2008, Nottingham launched an optional extra-curricular programme, the Nottingham Advantage Award (hereafter the Award). The aim of the Award was to provide undergraduate students with the opportunity to gain accreditation for learning outside of the formal curriculum that could enhance employability and career development (Baker \& Henson, 2010). Subsequently the Award has been opened up to postgraduate students. It has grown steadily (over 100 modules are now available) and is seen as a cornerstone not only of the University's employability strategy but also of internationalisation, volunteering and community engagement.

As of February 2012 there were 2000 students enrolled on the Award at the UK campus and over 300 students enrolled in China and Malaysia (both operating their first full-year of the programme following pilots in 2010-11).

The Award aims to provide a principled and process-driven pathway through the curriculum in the broad areas of:

- Preparation for professional life and lifelong learning [with an emphasis upon reflective practice]

- Service for the public good

- Personal development - the attitudes and skills to manage own growth (Report on the Nottingham Advantage Award for Management Board, February 2010).

Since inception, the Award has outgrown its original skills-focused learning outcomes and now offers a broad portfolio for capability development (community engagement, entrepreneurship, internationalisation, sustainability, global citizenship). It has shifted its position from a human capital perspective, in which advantage is the dominant discourse (the Award as an aid to securing better-paid employment), to a human development discourse in which its curriculum imagines "ethically inclusive and humanly rich goals for development" (Walker, 2012, p.388). The Award team talk of achievement but also of opportunity and contribution, finding inspiration from two notable authors:

"our campuses are producing citizens and this means we should ask what good citizens of the present day should be and should know" (Nussbaum, 1997, p.8);

"Development can be seen....as a process of expanding the real freedoms that people enjoy. Focussing on human freedoms contrasts with narrower views of development, such as identifying development with the growth of gross national product, or with the rise in personal incomes" (Sen, 1999, p.3).

At UNNC, the Award is open to students in their second, third and fourth years of study. First year students, who enter UNNC having completed the GaoKao, the National College Entrance Exam, are busy with the Student Personal Development Programme which includes modules on Chinese culture, careers, English for academic and professional purposes, and awards credit for club and society activities. For UNNC staff the Award can deepen international understanding and can make a specific contribution to learning needs identified as being specific to the Chinese context. For example, the Award supports the further development of language competency and can counteract the tendency for English language skills to decline from year two onwards once intensive language support is removed. The Award can develop professionalism, autonomous and reflective learning, equipping students to meet the different requirements of different types of company operating in different parts of the economy (Velde, 2009). The Award can add depth and 
breadth to the UNNC experience, supporting students to look beyond the minimum requirements for employment to the longer-term development of their capabilities.

\section{Research Aims}

This research aimed to explore how different stakeholders of the University of Nottingham understood employability, its relationship to the curriculum and where responsibility for employability sat. It was hoped that increased knowledge of these issues would enable the strategic development of the Nottingham Advantage Award to be responsive to stakeholder needs, concerns and priorities as well as to the ambitions of the University.

The objectives of the project were to describe and examine:

- Stakeholder views on an 'employability' curriculum (what kind of learning was valued).

- The perceived place of employability within the mainstream curriculum.

- Student and staff perspectives on the Nottingham Advantage Award.

- The role of personal and academic tutors in student self and professional development.

- Perceptions on current and future needs as well as challenges associated with student career support and employability.

\section{Research Methodology}

In 2011-12, qualitative research was undertaken to explore the understanding of employability in four teaching and learning units across the University's UK campus: History, Manufacturing, Materials and Mechanical Engineering, Mathematical Sciences and Sociology and Social Policy (the full results of this will be published separately).

The overall research methodology was triangulation: relating relevant issues and opinions as found in (1) the academic literature, (2) policy documents and (3) the research field work (Cohen, Manion \& Morrison, 2000). The research was approved by the School of Education at the University of Nottingham as complying with the ethical requirements of the British Educational Research Association.

The four schools were chosen by the Steering Group of the Nottingham Advantage Award to provide a range of views from different faculties, and as schools that (at that stage) did not have close links already to the Nottingham Advantage Award. There was little empirical evidence of attitudes towards employability in these schools. Senior managers were approached to obtain agreement to their school's participation.

The research was initially designed in two phases. Following a review of the existing literature, a series of Phase 1 interview schedules were produced that varied slightly for different stakeholder groups: administrative staff, academic tutors, students and employers. These were refined following discussions between two researchers and with input from careers service staff. The questions covered the definition of employability, its relationship to the academic curriculum, the role of academics in student self and professional development, the responsibilities of careers services, the expectations of employers, and the strengths and weaknesses of the Nottingham Advantage Award (see Appendix for the UNNC variants of the interview schedules).

The questions guided a semi-structured interview that provided scope for additional questions and comments. Phase 1 involved 29 interviews with stakeholders associated with History and Engineering. Interviews were audio recorded, transcribed and then coded for dominant themes and issues. 
In Phase 2, Q-Methodology was used (Brown, 1996). This involved the creation of statement banks about each of the issues that emerged from the Phase 1 coding. The Phase 2 participants (22 stakeholders from Mathematical Sciences and Sociology and Social Policy) were asked to rank order these statements using a Likert-type scale from 'most agree' to 'most disagree' on an eight-column grid (Cohen, Manion \& Morrison, 2000). This enabled the creation of a quantified attitude map of the domain of interest in relation to the Nottingham UK participants (to be published separately).

In January 2012 the opportunity arose to extend the research to UNNC (Phase 3). This was not part of the original project but was considered as an opportunity to enhance the value of the research and to increase the relevance of its findings. Using the Phase 1 design only, a further 19 interviews with three stakeholder groups (administrative staff, academic tutors and students) were conducted. The interview questions were amended slightly to reflect the different organisation of UNNC (see Appendix). To these were added the results of four informal interviews covering similar questions that were conducted with senior managers the previous year during the pilot phase of the Nottingham Advantage Award on the Ningbo campus. Q-Methodology was deliberately not used at UNNC as the 2012 researcher was inexperienced and it was considered important to gather direct views rather than views reflected through those of UK colleagues.

The UNNC interviews were transcribed, analysed and coded and were then compared against the overall results of Phases 1 and 2 in the UK, and against the literature on employability, higher education and the labour market in China. In addition to the themes that had emerged from the UK interviews, an additional group of China-specific themes were identified. This allowed us to see the similarities and differences in responses given by the stakeholders on the two campuses.

It is important to note that the researchers did not seek to investigate the ethnicity of those interviewed either at UNUK or at UNNC but were interested in the views of people working at a Sino-British university either as staff or as students. As previously indicated, the UNNC student population is overwhelmingly Chinese. However, Chinese students should not be seen as a homogenous group: "the Chinese learner may have certain identifiable characteristics, some of which might be related to culture, but they may also learn and behave differently in different situations, according to personal needs and situational demands" (Gu \& Schweisfurth, 2006, p.75). UNNC staff are more diverse; the Provost's report to Senate in June 2011 records that academic staff originate from 38 countries with only $18 \%$ from China (excluding Hong Kong, Macau and Taiwan). The impact of this was not explored.

UNNC has a different organisational structure to UNUK. Where possible, interviews were conducted with staff and students working in the same disciplinary areas (a future study may look into disciplinary difference in relation to employability). However, as in the UK, the researchers were dependent upon a snowballing strategy to secure participation, relying on recommendations and intervention from the careers service staff and a few participants (interviews at UNNC were conducted during an examination period).

The data from Phases 1 and 2 in the UK were combined for the analysis with more detailed analysis of the qualitative and quantitative data from the Phase 3 interviews at UNNC. Quantitative data is only included for the UK results where it does not cloud the results of the Q-Methodology, which measured varying strengths of opinion 


\section{Results}

Figure 1 shows the number of participants (University and represented stakeholder group) interviewed in each Phase of the study.

\begin{tabular}{|l|l|l|l|l|l|}
\hline & \multicolumn{5}{|c|}{$\begin{array}{l}\text { Stakeholders } \\
\text { (Total 74) }\end{array}$} \\
\cline { 2 - 6 } & A & T & S & E \\
\hline Phase 1 participants UNUK (Total 29) & \multicolumn{5}{|l|}{} \\
\hline History - 16 & 2 & 6 & 6 & 2 \\
\hline Mechanical, Materials and Manufacturing Engineering -13 & 2 & 5 & 4 & 2 \\
\hline Phase 2 participants UNUK (Total 22) & \multicolumn{5}{|l|}{} \\
\hline Mathematical Sciences - 14 & 2 & 5 & 5 & 2 \\
\hline Sociology and Social Policy - 8 & 2 & 2 & 3 & 1 \\
\hline Phase 3 participants UNNC (Total 23: 4 in 2011, 19 in 2012) & & & & \\
\hline Faculty of Science and Engineering & 1 & 4 & 1 & 0 \\
\hline Faculty of Arts and Humanities & & 6 & 1 & 0 \\
\hline Faculty of Social Sciences & & 1 & 3 & 0 \\
\hline Central Administration & 6 & & & 0 \\
\hline
\end{tabular}

$\mathrm{A}=$ administrative staff, $\mathrm{T}=$ academic tutors, $\mathrm{S}=$ students $\mathrm{E}=$ employers

Figure 1: Project Phases and number of participants

\section{Phases 1 and 2: combined summary of UNUK results}

In the UK, students most agreed with the Award being introduced to them at the beginning of their course; they believed employers valued most a set of generic skills and that individual academic schools needed tailor-made approaches to employability. Students strongly agreed with the idea that employability means to develop potential in various areas so that individuals acquire a special quality of mind and personality. The majority of students $(n=18$; $83 \%$ ) seemed to be open to new and fluid ideas on employability, although they defined this instrumentally, focusing on the Curriculum Vitae.

All of the seven employers interviewed in Nottingham highly agreed that what students did within their curriculum was linked to employability and that the development of students as reflective and critical thinkers was important. They noted the importance of teaching and learning methods in developing employability. Academic tutors overall tended towards neutrality on the links between curriculum and employability and the role of teaching and learning although only one tutor stated that "curriculum delivery is not connected to student employability". Employers also highlighted the importance of student societies. Together with tutors and administrative staff, employers believed that it was important that students started thinking about employability early on.

Both tutors and employers highly disagreed with the suggestion that graduate employability was mainly the responsibility of university careers services. However, employers thought that it was part of a tutor's role to inform students of employability and careers opportunities and training, whereas tutors opted for either disagree or mid-ground positions on such a responsibility with only five tutors seeing this as a clear part of their role $(n=18 ; 28 \%)$. 


\section{Phase 3: results of UNNC interviews with illustrative quotations}

All five students interviewed at UNNC offered an instrumental definition of employability, describing it as to gain a job and to have a strong Curriculum Vitae ("It is related to his knowledge, skills and ability which could help him fulfil in the work and present him well to the employers"). Two students (40\%) saw a distinction between employability and recruitability, one recognising that obtaining a job was not the same as working effectively while the other saw a status difference: "I can be recruited as a maybe a worker who washes dishes. But employable, maybe I will be employed as a manager".

All administrators and most academics ( $n=11: 67 \%$ ) used instrumental definitions of employability, although the abilities needed to obtain jobs were seen to include personal qualities. Several staff (3 administrators, 5 tutors; $44 \%$ of 18 staff interviewed) were concerned with institutional performance in employment metrics, something that did not feature in the Nottingham interviews:

According to the statistics, on this campus it's $100 \%$ for the past three years, but I personally think it's not accurate. It's not an accurate one because on our campus, we have $50 \%$ of students who go overseas to further study. So only $50 \%$ go to the job market. So those other $50 \%$, they still have to live on their parents to support them. (Administrator)

It's a key measure that is imposed on us by the Chinese Ministry of Education as to how many students either go on to further study or employment and it is tied in with measures around teaching quality. So employability is a very, very important metric for us in our setting. (Academic)

The majority of UNNC academics $(n=11 ; 72 \%)$ saw connections between the academic curriculum and learning for employability:

If we don't teach students the sort of skills which will get them jobs they will not do the courses. The idea that if you do Art degree you will learn less is not sustainable; there are not enough students who just do the subject because they love it. We need to teach them academic skills which have applicability in other areas of life - very general skills. We don't know where they're going to go or what they're going to do - Also China is changing, you can't predict what they will need across the next 40 years of their career. (Academic)

One academic talked about inter-disciplinary learning as a way of broadening the employability of graduates. Several $(n=18 ; 61 \%)$ stressed the differences between western and Asian cultural norms and learning styles, all judging that western learning was of benefit to the development of employability:

A lot of our students move into jobs where they either work with foreigners, or for foreigners, or in foreign countries, and I think our students do have an enormous advantage in that they now have interacted with foreigners, understand how foreigners think. They better understand what they shouldn't do and what they should do. (Academic)

This was reinforced by an Administrator who spoke of different Western and Chinese ways to achieve success and the need for students to recognise which method to use in which context.

However, as in the UK, there was disagreement about the responsibility for teaching or supporting employability. While most recognised there was an academic role, there were 
concerns about the crowded curriculum, but also about the ability of academics in less vocational areas to be sufficiently up to date (as one academic stated, "So I think we should stick to what we do best"). For two academics it was the structure of the programmes that affected their view of their role. They were teaching on foundation or mobility programmes in which students moved between campuses or schools. They felt that learning for employability fell into the remit of those teaching the students at later stages.

No employers were interviewed at Ningbo. However, several staff $(n=18 ; 39 \%)$ offered their perceptions of employer needs, believing that Chinese employers wanted ready-made employees:

they want them to be able to fit into a company, be able to work more or less straightaway with not that much guidance. They should actually know the framework already..... They're a little bit concerned about taking on interns because they're worried that they're going to have to devote staff time to training them and then they'll lose them straightaway. Actually I think staff retention is an issue that many of the local companies are concerned about. (Academic)

Most interviewees at UNNC ( $n=23 ; 82 \%)$ saw the Nottingham Advantage Award as a valueadded optional programme that allowed students to distinguish themselves from others. However, four interviewees (22\%; two tutors, one administrator and one student) supported the integration of the Award into the mainstream curriculum (largely on grounds of access):

So if it could be fitted within the curriculum smoothly, I think that would be the best place for it. If not and you have to do it as something separate and make it additional to the course, I don't think there's anything wrong with it but I just hate the idea of... I mean even if you have a slacker student, you still want them to be employed. I mean it might be that they're just not on the course that they actually want to be on, especially in China where it's the parents who have chosen their courses for them. (Academic)

If it is included in our degree course, other students can also join in. (Student)

Four staff members $(20 \%)$ felt that the speed at which the job market changed in China meant that retaining the Award outside of the curriculum allowed for greater flexibility and continual updating. It was important that the Award reflected current Chinese needs with content developed appropriately.

Aspects of a specifically Chinese context were raised frequently. Between one third and a half of interviewees mentioned the role of the family either in affecting learner expectations and/or in planning for and gaining employment:

We also hear quite a lot about the ideas that their parents have about what they should be doing in the future and that is a really huge issue in that the students themselves very often don't have a very clear idea of what they want to do but their parents and their grandparents very often do have a very clear idea of what they want them to do. So very often they're kind of pushed in that area. (Academic)

Normally lots of Chinese students when they are in year one, they are very confused. Maybe I think some students, they have dreams of what they should become and what they should do in the future. I think they are not their dreams. It's their parent's dreams. (Administrator) 
I mean okay, we have $100 \%$ employment rate for our students, but I think that's actually partly to do with family contacts as opposed to any help they're getting from the careers service here. (Academic)

All four of the senior managers interviewed in 2011 emphasised that the Nottingham Advantage Award would be important in developing learner autonomy:

I think here with Chinese students we do still have a problem with some basic core skills that we really try to get over and I think we're still struggling to break those twelve years of Chinese education. When my students bring things to me for instance and they say, 'But my teacher said there's one correct answer to every question'. It's a habit that we try and break to say, 'No. Actually there are many correct answers. Just some are more correct than others.' So those sort of basic thinking skills is something that we stress and I don't know that we have as much success with that as I would like. (Academic)

\section{Discussion}

The UNNC interviews were conducted after the UNUK data collection had been completed and the results analysed. This enabled the identification of commonalities and divergences between the two sets of stakeholder responses by campus as well as by stakeholder group. Overall, the students expressed similar views irrespective of their home campus. Instrumental definitions of employability were typical as was a belief that learning or preparation for employability should start at the beginning of their university careers. Every student struggled to see a difference between recruitability and employability with only one UNNC student offering a reasoned distinction.

There was more divergence between the views of UNUK and UNNC staff, with those at Ningbo being more comfortable with learning for employability within the academic curriculum than their colleagues in the UK. While UK tutors stated that graduate employability is not mainly the responsibility of careers services, they also did not see it as a dominant responsibility for either themselves or the academic curriculum. This apparent contradiction illustrates the tensions discussed in the research literature (Barrie, 2009; Yorke, 2010). The UNNC staff made frequent comments related specifically to China, suggesting a greater staff awareness of the economic and social challenges facing the country and an ability to see how their own work related to these (Bai, 2006, 2010).

The seven employers interviewed in the UK showed themselves to be in tune with the research literature in that they saw the academic curriculum as crucial in the development of student employability. They wanted to collaborate more closely with university staff. They talked of the value of extra-curricular activities and work experience but they also saw themselves as playing a major role in the development of graduates once in employment. UNNC staff were much more likely to agree that the academic curriculum should deliver employability than their UK colleagues, but, when giving their views on the needs of Chinese employers, they gave a greater emphasis to work-readiness at graduation. This fits with the cultural differences found by Shi and Sewell (2011) who defined UK students as 'customers' of higher education and Chinese students as 'products'. For example, while work experience is considered a crucial tool in the UK and west (e.g. as in the UK government's Higher Ambitions paper of 2009), it is not a usual expectation in China where most students proceed from school to university at age 17 and thence into work or postgraduate study. Chinese students are more likely to live with their parents than UK students during their studies (Velde, 2009). In this context, work-readiness becomes an expectation of a university education rather than of the add-ons to this education. Meeting this expectation is a challenge with Chinese employers reporting on staff shortages and the high-cost of in- 
employment training due to a "mismatch between the graduate outputs from the university sector in China and the type of employee needed" (Davies, Xinyan \& Wei 2012, p.2).

An unwillingness to fund workplace training may also be about access to 'elite' graduates. Different types of Chinese employers (foreign or state-owned, public or private) use higher education differently (Venter, 2003). Richer companies recruit from top universities and invest in training. Less secure companies cannot access elite graduates so easily but neither can they afford to invest in entry-level training. The resource divide between employers may perpetuate the inequalities of opportunity built into a hierarchical system of higher education (Velde, 2009).

In the UK, $40 \%$ of the interviewees $(n=51)$ spoke of the challenge of developing students as learners. The Nottingham Advantage Award was a mechanism to assist in this, supplementary to the critical thinking and other generic skills developed through the academic curriculum. But UK interviewees did not highlight learner autonomy as a developmental need unlike their UNNC colleague (and especially the senior staff interviewed in 2011) who seemed to agree that: "Independent and critical thinking is unfamiliar territory for most Chinese students, hindering their ability to gain a thorough understanding of the country's economic, social and political challenges" (Wu \& Morgan, 2011).

While specifically Asian values in education may be identified by western commentators (or, in this research, by commentators working within a western-style university in China), they need to be understood rather than problematised:

"It is not simply a question of understanding how Chinese cultural norms might impact on teaching and learning; it is equally important to understand the motivations and needs of particular groups of Chinese learners. Second, a support system is required in institutions to help learners overcome the stress and frustration caused by initial cultural shock and enables them to enjoy the professional and personal benefits of intercultural experiences. Such support needs to be both socially and academically targeted" (Gu \& Schweisfurth, 2006, p.88).

Student intercultural experiences at UNNC are limited while the student population remains predominantly mono-cultural. At the present time, the international staff are best placed to support students to 'enjoy the professional and personal benefits of intercultural experiences'. Hence it is important that they see their role as going beyond the support or delivery of an academic curriculum narrowly-conceived.

Careers in China are no longer about a series of progressive moves towards seniority in the same company (Jiangqin \& Zhiwen, 2011). Jiangqin and Zhiwen use the notion of the 'protean career' (from the shape-changing Greek god Proteus) to represent the individual's need to adapt to change on various levels: individual, company or industry, society. This adaptability requires a "strong commitment to learning continuously" (Velde, 2009, p.35). Academics understand this at UNNC. They recognise but may be nervous about their responsibility for developing their students as all-round learners and hence see the Nottingham Advantage Award as a safe space where up to date learning for employability can be delivered. Despite their nervousness, they are less likely to see a disconnect between the academy and the workplace than are their UK colleagues.

The differences we found in the perspectives of UNNC and UNUK staff, and of university stakeholders and employers, resonate with the wider debate about the purpose of higher education and whether or not it is a public or private good (Calhoun, 2006). This debate fuels an 'information asymmetry' that requires resolution. Universities need to focus efforts upon providing quality information and guidance to their students to ensure that they understand 
the skills or capabilities required by employers (Li, Morgan \& Ding, 2008). For a transnational university like Nottingham there is a prior stage of reducing internal information asymmetries between different stakeholder groups within and between campuses in order "to bring together the best of UK and Chinese educational values and practices" (Ennew \& Fujia, 2009, p.30).

\section{Limitations}

This was a small study limited to two campuses of one university. The research was designed in two phases solely for the UK campus and only subsequently expanded when an opportunity arose to conduct and then incorporate further interviews at UNNC. Participant numbers were small and spread widely across stakeholder groups. Participants were also those sympathetic to the research aims, hence their agreement to be interviewed. This may have bearing on the results in that everyone had views on employability and were willing to engage in discussion. However, the research captured voices from across the University of Nottingham and was able to nuance these by stakeholder category and by learning location.

\section{Conclusion}

This study revealed a disconnect between the opinions of university stakeholders in the UK and China and the theoretical underpinning of the Nottingham Advantage Award which was shifting in line with the research literature from skills to capabilities and from human capital to human development. While there was broad agreement about the significant contribution that higher education makes to graduate employability, there were contested positions on the issue of visibility (the role of the academic curriculum in employability), responsibility (whose job is it to teach employability) and understanding (ranging from instrumental to holistic definitions). Both the research literature and the UK employers agreed that the academic curriculum was the essential location for employability learning, while students and tutors at both locations expressed polarised opinions (with UNNC colleagues being more sympathetic to this than UK colleagues but also nervous about the responsibility).

Additional themes and emphasis emerged from the UNNC interviews to indicate a consciousness of difference on the part of staff and students. Discussing the Award, several commented on the need to ensure that it was fit for purpose in its Chinese setting. The research suggested that, for a global institution like Nottingham, it is crucial to understand the host as well as the international context in order to enable students to forge meaningful careers in China and beyond. This is a challenge. Parental influence featured several times in the UNNC interviews but not once in those from the UK. While the Chinese government may have removed the job assignment system, a form of parental assignment clearly exists and must be understood within its context (e.g. one-child policy, high income sacrifice).

In addition to revealing both convergence and divergence between stakeholder views on the two campuses, this research also revealed disciplinary differences which require further investigation. Research is needed to illustrate how understandings of employability and its place within the academic curriculum vary between arts and sciences, between vocational and non-vocational courses and the extent to which disciplinary differences are enlarged or reduced by the cultural context of each home campus (which may also include national professional bodies). Follow-up research would also be useful to explore the impact of the Nottingham Advantage Award on each campus as student recruitment increases and the Award becomes a routine part of the student experience. The Award is well-placed to support Nottingham in reducing those information asymmetries, but only if its own development is informed by the research literature and by the opinions and concerns of its stakeholders. 


\section{References:}

Bai, L. (1998). Monetary reward versus the national ideological agenda: career choice among Chinese university students. Journal of Moral Education 27(4), 524 - 540.

Bai, L. (2006). Graduate unemployment: Dilemmas and challenges in China's move to mass higher education. China Quarterly 185, 128-144.

Bai, L. (2010). Human Capital or Humane Talent? Rethinking the Nature of Education in China from a Comparative Historical Perspective. Frontiers of Education in China $5(1), 104-129$.

Baker, G. \& Henson, D. (2010). Promoting employability skills development in a researchintensive university. Education + Training 52 (1), 62-75.

Barrie, S.C. (2009). Setting and monitoring academic standards for Australian higher education (Memorandum to AUQA in response to the Discussion Paper). Retrieved from: www.auqa.edu.au/qualityenhancement/academicstandards/responses/39.pdf 30 May 2011

Brown, S.R. (1996). Q-Methodology and Qualitative Research. Qualitative Health Research $6(4), 561-567$.

Calhoun, C. (2006). The university and the public good. Thesis Eleven 84, 7-43.

Cohen, L., Manion, L. \& Morison, K. (2000). Research Methods in Education. (5 $5^{\text {th }}$ ed.) London: Routledge Falmer.

Davies, D., Xinyan, Z. \& Wei, L. (2012). Skills Shortages in China? A Conceptual Model. Retrieved 17 February 2012 from: http://www.wbiconpro.com/429-Doug.pdf

Department for Business, Innovation and Skills, United Kingdom. (2009). Higher Ambitions: the future of universities in a knowledge economy. Retrieved 10 February 2012 from: http://www.bis.gov.uk/assets/BISCore/corporate/docs/H/09-1447-higher-ambitions

Ennew, C.T. \& Fujia, Y. (2009). Foreign Universities in China: a case study. European Journal of Education 44 (1), 21-36.

Harvey, L. (2005). Embedding and Integrating Employability. New Directions for Institutional Research 128 (2005), 13-28.

Huang, F. (2007). Internationalization of Higher Education in the Developing and Emerging Countries: A Focus on Transnational Higher Education in Asia. Journal of Studies in International Education 11, 421-432.

Gu, Q. \& Schweisfurth, M. (2006). Who adapts? Beyond Cultural Models of 'the' Chinese Learner. Language, Culture and Curriculum 19 (1), 74-89.

Jiangqin, X. \& Zhiwen, G. (2011). Employability Development of Graduates in China. International Conference on Management and Service Science, 1-4.

Li, F. \& Morgan, W.J. (2008). Private higher education in China: access to quality higher education and the acquisition of labour market qualifications by low-income students. Education, Knowledge and Economy 2, 27-37.

Li, F., Ding, X. \& Morgan, W.J. (2008). Job Search Channels and Educational Level in China: Testing the Screening Hypothesis. China: An International Journal 6 (2), 261277. 
Li, F., Ding, X. \& Morgan, W.J. (2009). Higher Education and the starting wages of graduates in China. International Journal of Educational Development 29, 374-381.

Li, F., Morgan, W.J. \& Ding, X. (2008). The expansion of higher education, employment and over-education in China. International Journal of Educational Development 28, 687697.

Li, F., Zhao, Y. \& Morgan, W.J. (2011). The rate of return to educational investment in China: a comparative commentary. Education, Knowledge and Economy 5 (1-2), 45-52.

Nussbaum, M. (1997). Cultivating Humanity. A Classical Defence of Reform in Liberal Education. Harvard:Harvard University Press.

OBHE (The Observatory on Borderless Higher Education). (2012). International Branch Campuses: Data and Developments. Retrieved 20 February 2012 from: http://www.obhe.ac.uk/documents/view details?id=894.

Olaniyan, D.A. \& Okemakinde, T. (2008). Human Capital Theory: Implications for Educational Development. Pakistan Journal of Social Sciences 5 (5), 479-483.

Schuller, T. \& Watson, D. (2009). Learning Through Life: Inquiry into the Future for Lifelong Learning. Leicester: NIACE.

Sen, A. (1999). Development as Freedom. Oxford: Oxford University Press.

Shi,J.J. \& Sewell, J.P. (2011) In search of the entrepreneurial spirit in China. Journal of Chinese Entrepreneurship, 3 (1), 58-71.

Velde, C. (2009). Employers' Perceptions of Graduate Competencies and future trends on higher vocational education in China. Journal of Vocational Education and Training $61(1), 35-51$.

Venter, K. (2003). Building on formal education: Employers' approaches to the training and development of new recruits in the People's Republic of China. International Journal of Training and Development 7 (3), 186-202.

Walker, M. (2012). A capital or capabilities education narrative in a world of staggering inequalities? International Journal of Educational Development, 32, 384-393.

Wu, B. \& Morgan, W.J. (2011) Comment: There's more to life than textbooks. China Daily. November 18-24, 2011.

Yorke, M. (2010). Employability: aligning the message, the medium and academic values. Journal of Teaching and Learning for Graduate Employability. 1(1), 2-12. 